\title{
Meta
}

Journal des traducteurs

Translators' Journal

WÜRSTLE, Regine (1992) : Überangebot und Defizit in der

Wortbildung : eine Kontrastive Studie zur Diminutivbildung

im Deutschen, Französischen und Englischen, Frankfurt am

Main, Peter Lang Verlag, Bonner romanistische Arbeiten, Band

42,257 p.

\section{Isabelle Cousineau}

Volume 38, numéro 3, septembre 1993

URI : https://id.erudit.org/iderudit/002422ar

DOI : https://doi.org/10.7202/002422ar

Aller au sommaire du numéro

Éditeur(s)

Les Presses de l'Université de Montréal

ISSN

0026-0452 (imprimé)

1492-1421 (numérique)

Découvrir la revue

Citer ce compte rendu

Cousineau, I. (1993). Compte rendu de [WÜRSTLE, Regine (1992) : Überangebot und Defizit in der Wortbildung : eine Kontrastive Studie zur Diminutivbildung im Deutschen, Französischen und Englischen, Frankfurt am Main, Peter Lang

Verlag, Bonner romanistische Arbeiten, Band 42, 257 p.] Meta, 38(3), 564-565.

https://doi.org/10.7202/002422ar d'utilisation que vous pouvez consulter en ligne. 
WÜRSTLE, Regine (1992): Überangebot und Defizit in der Wortbildung: eine Kontrastive Studie zur Diminutivbildung im Deutschen, Französischen und Englischen, Frankfurt am Main, Peter Lang Verlag, Bonner romanistische Arbeiten, Band 42, 257 p.

Cet ouvrage de linguistique contrastive examine l'utilisation des diminutifs en allemand, en français et en anglais. Que l'on comprenne ici les diminutifs de substantifs tant synthétiques (avec suffixe) qu'analytiques (avec épithète signifiant «petit»). Après avoir donné un aperçu des théories et concepts linguistiques qui touchent à ce type de formation de mots, l'auteur présente les conditions d'utilisation des diminutifs tant au niveau du système de la langue qu'au niveau de la norme. On observe vite que l'allemand utilise abondamment les diminutifs, alors que ceux-ci ne sont plus formés spontanément dans les deux autres langues. Par une étude de textes allemands et de leurs traductions, l'auteur veut donner un portrait fidèle des restrictions sémantiques et d'usage qui régissent la formation des diminutifs, et étudier la façon dont les diminutifs allemands, si courants, peuvent être exprimés en français et en anglais où ils font cruellement défaut. Le corpus comprend cinq œuvres de Max Frisch, deux cuvres de Hermann Hesse et deux œuvres de Thomas Mann, ainsi que leurs traductions par neuf traducteurs pour les versions françaises et quatre pour les versions anglaises. L'auteur souhaite que les constats de son étude puissent servir à l'édification d'une grammaire à l'usage des traducteurs.

Certes, l'étude de Regine Würstle n'est pas la première en son genre; elle fait suite à l'ouvrage de Maja Fischer (1962), qui analysait les diminutifs dans Romeo und Julia auf dem Lande de Gottfried Keller, et dans six versions françaises de cette nouvelle. Mais cette fois, le corpus est beaucoup plus large. Les linguistes sauront apprécier l'effort de Regine Würstle de se démarquer de la morphologie traditionnelle, qui, dans une perspective diachronique, s'intéressait aux diminutifs déjà lexicalisés. C'est de la productivité des diminutifs dont il est ici question. Le degré de productivité des diminutifs synthétiques aurait des conséquences directes sur l'emploi des diminutifs analytiques: l'auteur observe que ces deux procédés se complètent en allemand, le premier ayant toujours une connotation affective; en français l'adjectif «petit» s'est doublé d'une valeur affective, ce 
qui permet aux diminutifs analytiques de remplacer dans une large mesure les diminutifs synthétiques, phénomène que l'on retrouve en anglais avec «little», qui peut signifier beaucoup plus que «small». Qu'en est-il des préfixes à valeur diminutive? L'absence de ce procédé dans le corpus choisi ne nous permet pas de le savoir.

Et c'est bien là la plus grande faiblesse de cet ouvrage, que de s'intéresser principalement aux diminutifs formés avec des suffixes au détriment de formulations équivalentes plus vivantes mais moins facilement repérables. Le corpus composé exclusivement d'œuvres littéraires illustre bien l'emploi des suffixes «-chen» et «-lein» en allemand, mais il est loin de mettre au jour toutes les ressources du français et de l'anglais pour exprimer l'idée de petitesse, avec ou sans valeur hypocoristique, péjorative ou neutralisante. (Pensons, par exemple, à la série d'épithètes anglais, familiers ou non, qui peuvent remplacer «little»: bit, tiny, teeny, wee, teensy, weenie, weensy, measly, minor, minute, midget, slight, small-time, qui ne sont pas examinés à la loupe.) Ainsi le traducteur qui, aux prises avec un diminutif allemand dans un texte littéraire ou pragmatique, consulte Überangebot und Defizit in der Wortbildung pour éclairer son choix de traduction, risque fort de devoir poursuivre sa recherche par d'autres moyens. En fin de compte, cet ouvrage qui voulait rapprocher la linguistique de la traductologie profitera peut-être davantage aux linguistes qu'aux traducteurs.

ISABELLE COUSINEAU

Montréal, Canada 